\title{
Prevalence and implications of elevated microsatellite alterations at selected tetranucleotides in cancer
}

\author{
M M C Watson ${ }^{1,2}$, M Berg ${ }^{1,2,3}$ and K Søreide ${ }^{*, 1,2,4}$ \\ ${ }^{1}$ Department of Gastrointestinal Surgery, Stavanger University Hospital, Stavanger 4068, Norway; ${ }^{2}$ Gastrointestinal Surgical \\ Research Unit, Molecular Lab, Hillevåg, Stavanger University Hospital, Stavanger 4068, Norway; ${ }^{3}$ Centre of Organelle Research, \\ University of Stavanger, Stavanger 4068, Norway and ${ }^{4}$ Department of Clinical Medicine, University of Bergen, Bergen 5020, \\ Norway
}

Elevated microsatellite alterations at selected tetranucleotides (EMAST), a variation of microsatellite instability (MSI), has been reported in a variety of malignancies (e.g., neoplasias of the lung, head and neck, colorectal region, skin, urinary tract and reproductive organs). EMAST is more prominent at organ sites with potential external exposure to carcinogens (e.g., head, neck, lung, urinary bladder and colon), although the specific molecular mechanisms leading to EMAST remain elusive. Because it is often associated with advanced stages of malignancy, EMAST may be a consequence of rapid cell proliferation and increased mutagenesis. Moreover, defects in DNA mismatch repair enzyme complexes, TP53 mutation status and peritumoural inflammation involving T cells have been described in EMAST tumours. At various tumour sites, EMAST and high-frequency MSI share no clinicopathological features or molecular mechanisms, suggesting their existence as separate entities. Thus EMAST should be explored, because its presence in human cells may reflect both increased risk and the potential for early detection. In particular, the potential use of EMAST in prognosis and prediction may yield novel types of therapeutic intervention, particularly those involving the immune system. This review will summarise the current information concerning EMAST in cancer to highlight the knowledge gaps that require further research.

Microsatellites are repeating units of one to six base pairs, which are ubiquitous, abundant and repeated several times in eukaryotic genomes. These repeats are prone to errors during DNA replication, and the failure to correct such errors results in microsatellite instability (MSI). Since its initial description as a form of genetic instability in colorectal cancer (CRC), MSI has been linked to a number of phenotypic characteristics and clinicopathological features of tumours (Sinicrope and Sargent, 2012). The prognostic and predictive relevance of MSI in CRC has been well documented (Sinicrope and Sargent, 2012). In CRC, MSI is the hallmark of forms of hereditary non-polyposis CRC (HNPCC; or Lynch syndrome) caused by germline mutations in mismatch repair (MMR) genes. MSI is also detected in 15\% of sporadic CRC cases, usually as a consequence of epigenetically silenced MMRs (Sinicrope and Sargent, 2012). Furthermore, the presence of MSI has been demonstrated in other cancers, including endometrial, ovarian and urinary tract cancers. Currently, MSI appears to be a genetic aberration found in a wide range of human solid tumours that is best defined in the context of colorectal neoplasia; at tumour sites other than CRC, the clinical relevance and frequency of MSI are variable (Catto et al, 2003; Pal et al, 2008; Diaz-Padilla et al, 2013). In the clinical setting, such as when screening for CRC, HNPCC or sporadic MSI, MSI is usually classified as mononucleotide and dinucleotide repeats (Umar et al, 2004). Recently, a number of reports have also documented instability at specific tetranucleotide repeats, a phenomenon termed elevated microsatellite alterations at selected tetranucleotide repeats (EMAST). As an emerging specific form of genetic alteration, EMAST remains poorly described. However, EMAST may hold clues for deeper insights into the roles of MSI in cancer 
biology, thus facilitating improved preventive, therapeutic and prognostic/predictive strategies in human cancer. This review aims to concisely present the current knowledge concerning EMAST in human solid cancers; we briefly present the proposed molecular mechanisms and describe the potential clinical implications for human cancer.

\section{MICROSATELLITES, REPEAT SIZE AND INSTABILITY}

During DNA replication, microsatellites are prone to erroneous duplication, which involves the addition or deletion of one or several repeated units, and the failure of DNA proofreading mechanisms to correct such errors results in instability at microsatellites. Microsatellite alterations, such as the insertion/ deletion of a repeat, can produce deleterious effects via the induction of strand slippage and frameshift mutations when a protein-coding region is affected (Saeterdal et al, 2001; Kim et al, 2013). The results of such effects range from changes in the physical and chemical properties of the translated proteins to interference with transcription at promoter sites or the translation of truncated and dysfunctional proteins.

Generally, repetitive elements can occur in a variety of patterns and distributions (i.e., tandem, dispersed and paralogues). These elements constitute as much as $50 \%$ of the genome, and approximately one-fourth of empirically defined human promoters are surrounded by or contain clustered repetitive elements. However, the genomic distribution of microsatellites is rather random; mononucleotides, dinucleotides and tetranucleotides are primarily found in intronic and intergenic noncoding regions, whereas other microsatellites (trinucleotides and hexanucleotides) are located more abundantly within sequences involved in gene transcription (Subramanian et al, 2003).

Previous attempts at defining MSI have not produced straightforward results. Following the first MSI international workshop at the National Cancer Institute (NCI) at Bethesda in 1998, the 2004 revised NCI/Bethesda microsatellite screening panel (Umar et al, 2004), which is based on five mononucleotide and dinucleotide microsatellites, defined 'classical' MSI as highfrequency (MSI-H; $\geqslant 2$ out of 5 markers are unstable or $\geqslant 40 \%$ ), low-frequency (MSI-L; 1 out of 5 markers is unstable or $\geqslant 20 \%$ and $<40 \%$ ) or microsatellite-stable (MSS; no unstable markers detected). In CRC, there is a consensus on the definitions of MSI for clinical use (Umar et al, 2004), although defining the different degrees of instability remains a matter of controversy. Based on the Bethesda panel, MSS, MSI-L and MSI-H tumours contain different numbers of altered microsatellites, suggesting that these forms of MSI represent separate phenomena, at least at the molecular level. However, MSS tumours and MSI-L unstable tumours are typically grouped together, because both present similar clinical forms and gross abnormalities. Notably, MSI-L is generally detected only when dinucleotide markers are used, and some authors have disputed the existence of MSI-L completely (Kim et al, 2013). MSI is found with the highest frequency in mononucleotide repeats, which are also the most frequently occurring nucleotide repeats throughout the genome. Notably, tetranucleotide repeats occur at a much lower frequency than mononucleotide repeats, and it is not known whether forms of MSI involving nucleotide repeats of different sizes share common underlying mechanisms. However, the most clinically relevant microsatellites studied in cancer are composed of mononucleotide (e.g., $G_{n}$ ), dinucleotide (e.g., $C_{n}$ ) or tetranucleotide (e.g., $\mathrm{AAAG}_{\mathrm{n}}$ ) repeats. Variations in the number of repeats in microsatellite sequences among the population are defined as microsatellite polymorphisms, as opposed to MSI, which refers to such alterations within multiple cells of the same individual (e.g., when comparing tumour and normal tissues). Instability at tetranucleotides represents a variation of MSI that was not addressed by the Bethesda definitions (Umar et al, 2004), which are based on mononucleotide and dinucleotide markers. However, in most EMAST-associated cancers, instability occurs at loci containing $\mathrm{AAAG}_{\mathrm{n}}$ or $\mathrm{ATAG}_{\mathrm{n}}$ repeats.

PREVALENCE AND RELEVANCE OF EMAST IN HUMAN CANCERS

EMAST has been reported in several cancers of solid organs (Figure 1), including the colorectum (Haugen et al, 2008; Devaraj et al, 2010; Lee et al, 2010; Lee et al, 2012), lungs (Ahrendt et al, 2000; Xu et al, 2001; Arai et al, 2013), ovaries (Singer et al, 2004), bladder (Xu et al, 2001; Danaee et al, 2002; Catto et al, 2003; Burger et al, 2006a), prostate (Perinchery et al, 2000; Burger et al, 2006b; Azzouzi et al, 2007), kidney (Xu et al, 2001; Catto et al, 2003), head and neck (Xu et al, 2001; Temam et al, 2004), nonmelanoma skin (Danaee et al, 2002) and uterus (Choi et al, 2008). The estimated prevalence of EMAST according to previously reported studies is presented in Table 1 . In fact, the reported prevalence and relationship between EMAST and clinicopathological features and molecular mechanisms vary considerably across tumour sites (Figure 1).

CRCs. Presumably because of the great impact that MSI has had on the understanding of human cancer biology, the vast majority of EMAST-related reports in the scientific literature concern CRC. EMAST is found most frequently $(>60 \%)$ in advanced-stage CRC with poor tumour differentiation (Lee et al, 2010). The documented presence of EMAST in adenomas has been inconsistent, with reports ranging from $0 \%$ (Lee et al, 2012) to 33\% (Lee et al, 2010). The overall frequency of EMAST in CRC is much higher (up to 60\%) than the frequency of classical MSI-H (usually 15-20\%) (Yamada et al, 2010), and EMAST occurs at high rates in rectal cancers (Devaraj et al, 2010). EMAST is associated with the MSI-L classification and demonstrates a worse prognosis with a shorter time to recurrence and development of distant metastasis in stage II and III CRC (Garcia et al, 2012). This worse prognosis is observed regardless of the association of EMAST with greater infiltration of CD8 $+\mathrm{T}$ cells in both the tumour and surrounding stroma (Devaraj et al, 2010; Lee et al, 2012), a feature usually associated with better prognosis in CRC. Thus the dual role of inflammation in this setting warrants further investigation.

Respiratory tract cancers. The reported frequency of EMAST in lung cancers ranges from 32\% to 64.5\% (Ahrendt et al, 2000; $\mathrm{Xu}$ et al, 2001; Woenckhaus et al, 2003; Arai et al, 2013). However, there appears to be a distinction between EMAST and MSI-H, and mutations in TP53 are common in EMAST cancers (Ahrendt et al, 2000; Xu et al, 2001; Woenckhaus et al, 2003). EMAST was found to be most prevalent in cases of the squamous subtype and early stage disease (Xu et al, 2001; Woenckhaus et al, 2003; Arai et al, 2013), although it was associated with higher rates of lymph node metastasis in another study (Woenckhaus et al, 2003). Additionally, one study found a higher incidence of previous cancer history in patients with EMAST (Arai et al, 2013), potentially suggesting a 'field defect' or cancer susceptibility related to EMAST.

Kidney and urinary tract cancers. The frequency of EMAST in cancers of urogenital organs is markedly lower compared with that in other solid tumours and is higher in the lower urinary tract (urinary bladder) than the upper urinary tract (kidneys, ureters and renal pelvis) (see Table 1, Figure 1).

In bladder cancer, EMAST-positive tumours (approximately one-third of bladder tumours) have been associated with TP53 mutations and non-invasive lesions (Danaee et al, 2002). However, a much lower EMAST frequency (5.3\%) was demonstrated in a large, non-selected cohort of urothelial bladder cancers, and 


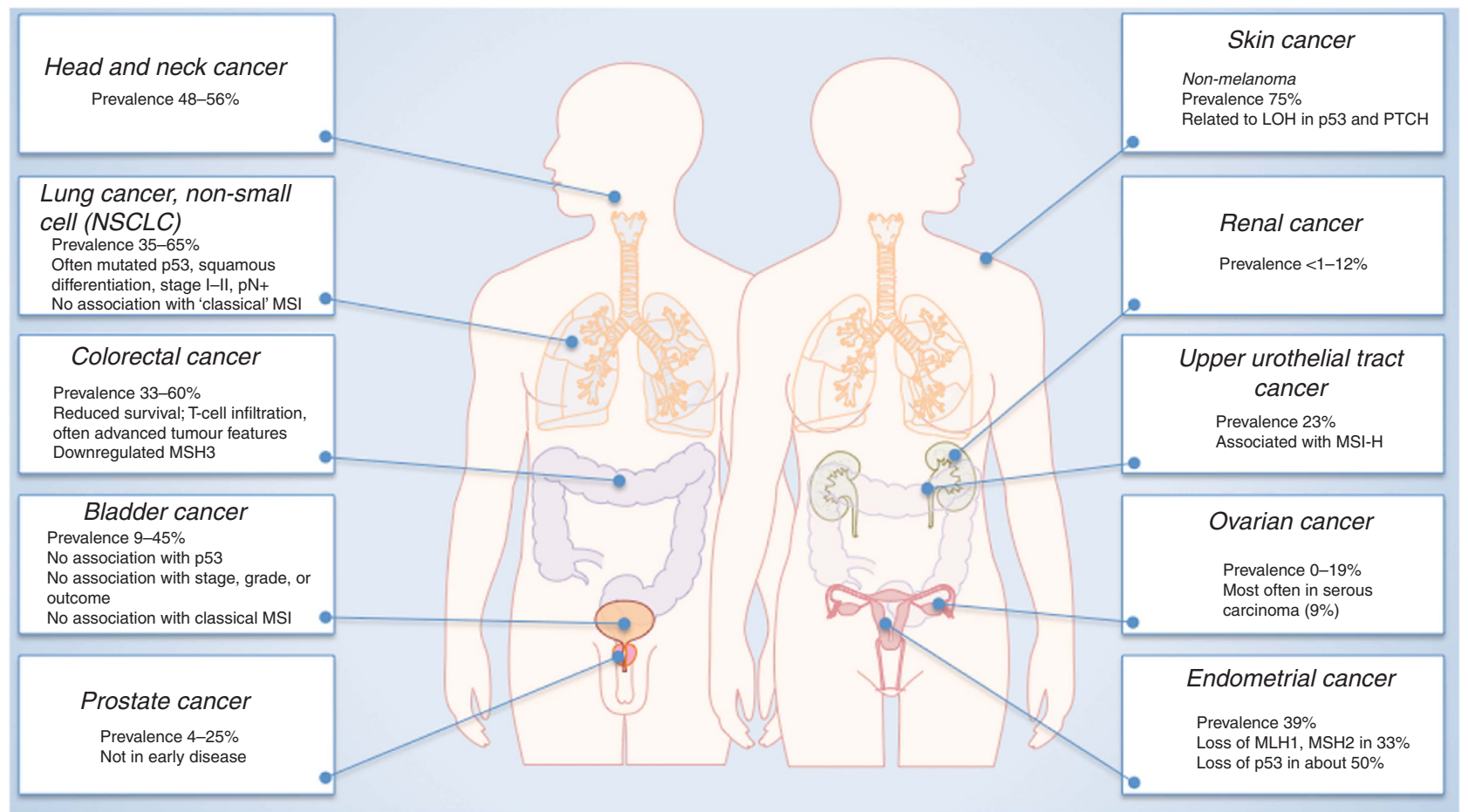

Figure 1. Prevalence and main observed features of EMAST in human solid cancers.

\begin{tabular}{|c|c|c|c|c|}
\hline Site & Author, year & Cohort size (n) & Definitions & Prevalence (\%) \\
\hline Bladder & $\begin{array}{l}\text { Xu et al, } 2001 \\
\text { Burger et al, 2006a, b } \\
\text { Catto et al, } 2003 \\
\text { Danaee et al, } 2002\end{array}$ & $\begin{array}{l}38 \\
117 \\
89 \\
57\end{array}$ & $\begin{array}{l}\geqslant 1 / 12 \text { markers unstable } \\
\geqslant 1 / 10 \text { markers unstable } \\
\geqslant 1 / 8 \text { markers unstable } \\
\geqslant 1 / 7 \text { markers unstable }\end{array}$ & \begin{tabular}{|l|}
$21 \%$ \\
$9 \%$ \\
$45 \%$ \\
$44 \%$ \\
\end{tabular} \\
\hline Colorectal & $\begin{array}{l}\text { Lee et al, } 2010 \\
\text { Lee et al, } 2012 \\
\text { Devaraj et al, } 2010 \\
\text { Haugen et al, } 2008\end{array}$ & $\begin{array}{l}108 \\
108 \\
147 \text { (only rectal) } \\
117\end{array}$ & $\begin{array}{l}\geqslant 2 / 5 \text { markers } \\
\geqslant 2 / 5 \text { markers } \\
\geqslant 2 / 5 \text { markers } \\
\geqslant 1 / 7 \text { markers unstable }\end{array}$ & $\begin{array}{l}50 \% \\
50 \% \\
33 \% \\
60 \% \\
\end{array}$ \\
\hline NSCLC & $\begin{array}{l}\text { Xu et al, } 2001 \\
\text { Arai et al, } 2013 \\
\text { Ahrendt et al, } 2000\end{array}$ & $\begin{array}{l}47 \\
65 \\
88\end{array}$ & $\begin{array}{l}\geqslant 1 / 12 \text { markers unstable } \\
\geqslant 1 / 10 \text { markers unstable } \\
\geqslant 1 / 13 \text { markers unstable }\end{array}$ & \begin{tabular}{|l|}
$51 \%$ \\
$65 \%$ \\
$35 \%$ \\
\end{tabular} \\
\hline Prostate & $\begin{array}{l}\text { Burger et al, 2006a, b } \\
\text { Azzouzi et al, } 2007 \\
\text { Perinchery et al, } 2000\end{array}$ & $\begin{array}{l}81 \\
50 \\
40\end{array}$ & $\begin{array}{l}\geqslant 1 / 10 \text { markers unstable } \\
\geqslant 2 / 4 \text { markers } \\
\geqslant 1 / 4 \text { markers }\end{array}$ & \begin{tabular}{|l|}
$5 \%$ \\
$4 \%$ \\
$25 \%$ \\
\end{tabular} \\
\hline Renal & $\begin{array}{l}\text { Xu et al, } 2001 \\
\text { Catto et al, } 2003\end{array}$ & $\begin{array}{l}25 \\
71 \text { (upper urinary tract) }\end{array}$ & $\begin{array}{l}\geqslant 1 / 12 \text { markers unstable } \\
\geqslant 1 / 8 \text { markers unstable }\end{array}$ & $\begin{array}{l}12 \% \\
23 \%\end{array}$ \\
\hline Head and neck & $\begin{array}{l}\text { Xu et al, } 2001 \\
\text { Temam et al, } 2004\end{array}$ & $\begin{array}{l}18 \\
54\end{array}$ & $\begin{array}{l}\geqslant 1 / 12 \text { markers unstable } \\
\geqslant 1 / 5 \text { markers }\end{array}$ & $\begin{array}{l}56 \% \\
48 \%\end{array}$ \\
\hline Non-melanoma skin & Danaee et al, 2002 & 61 & $\geqslant 1 / 7$ markers unstable & $75 \%$ \\
\hline Ovarian & Singer et al, 2004 & 53 & $\geqslant 1 / 6$ markers unstable & $19 \%$ \\
\hline Endometrial & Choi et al, 2008 & 39 & $\begin{array}{l}\geqslant 1 / 6 \text { markers unstable and no instability in mononucleotides and } \\
\text { dinucleotides }\end{array}$ & $39 \%$ \\
\hline
\end{tabular}

EMAST was not found to be associated with TP53 status (Burger et al, 2006a). In the urinary tract, EMAST appears to be unrelated to classical MSI and occurs less frequently in the renal pelvis (Catto et al, 2003). No firm associations between EMAST and clinicopathological features or clinical outcomes have been reported (Danaee et al, 2002; Catto et al, 2003; Burger et al, 2006a). The reported EMAST frequency in renal cell carcinomas is very low, ranging from $<1 \%$ (Stoehr et al, 2012) to $12 \%$ (Xu et al,
2001). Based on the limited available evidence, it appears that the prevalence of EMAST decreases from the upper to the lower urinary tract, with no solid clinical relationships or molecular mechanisms having been established in this area.

Reproductive organs. In cancers of the reproductive organs, EMAST occurs slightly more often in malignancies of the female reproductive organs, such as the ovaries (13\%, Singer et al, 2004) 
and uterus (38.5\%, Choi et al, 2008), compared with the male reproductive organs, although the overall available literature remains limited.

Classical MSI is noted in approximately $12 \%$ of ovarian cancers (Pal et al, 2008) and is most frequently associated with the non-serous histological type. In contrast, EMAST appears predominantly in the serous subtype of ovarian cancers; no EMAST has been found in non-serous carcinomas (Singer et al, 2004).

Approximately $15 \%$ of endometrial cancers exhibit MSI-H, but there are conflicting reports of the relation to clinical outcome (DiazPadilla et al, 2013). EMAST has been reported at a higher frequency (39\%) than classical MSI, but these two markers showed no correlation in type I endometrial carcinomas. Furthermore, most (70\%) EMASTpositive tumours exhibited normal expression of both MSH2 and MLH1 in immunohistochemical analyses (Choi et al, 2008).

In prostate cancer, MSI is generally prevalent at dinucleotide tandem repeats and is less common in trinucleotide and tetranucleotide repeats (Perinchery et al, 2000). According to most reports, the frequency of EMAST in prostate cancer is $<5 \%$ (Terrell et al, 1995; Burger et al, 2006b; Azzouzi et al, 2007). In prostate cancer, EMAST is related neither to MSI nor to defects in MMR proteins, TP53 mutational status or any histopathological features (Burger et al, 2006b).

Other malignancies. Instabilities in tetranucleotide repeats have been reported in both the MSI-H and MSI-L types of gastric tumours, although EMAST has not been specifically investigated in this setting (Kim et al, 2001). In a small study of 22 pheochromocytomas (Kupka et al, 2008), 2 patients demonstrated MSI in 1 and 2 of three tetranucleotide repeats (D2S443, D16S752 and D21S1436) investigated; both cancers were defined as MSI-L by the Bethesda panel. None of the endocrine tumours in that study exhibited instability in the tetranucleotide markers used, although 13\% were classified as MSI-H (Kupka et al, 2008).

EMAST was also analysed in one study of non-melanoma skin cancer, where it was found at a high incidence (75\%) and was associated with TP53 or PTCH (patched gene) loss of heterozygosity (Danaee et al, 2002). PTCH acts as receptor in the sonic hedgehog signalling pathway, and loss-of-function mutations in $\mathrm{PTCH}$ contribute to skin cancer development. The PTCH gene harbours mutational hot-spot residues and regions, including a slippage-sensitive sequence at the $\mathrm{N}$-terminus (Lindstrom et al, 2006).

EMAST frequencies in head and neck cancers have been reported to range from $48 \%$ to $56 \%$ (Xu et al, 2001; Temam et al, 2004). Of clinical relevance was one report showing that patients with histologically proven $(=\mathrm{R} 0)$ radical and curative surgery, but who displayed EMAST at the resection margins, had a higher risk of tumour recurrence (Temam et al, 2004). 'Molecular-positive' resection margins may thus be proposed as grounds for more aggressive treatment or surveillance if validated as a broadened concept.

More recently, the length of an AAAG tetranucleotide repeat tract and polymorphisms in a tetranucleotide repeat, both located within the KCNQ1OT1 gene, have been shown to correlate with an increased risk of breast cancer (Karimi et al, 2013) and hepatocellular carcinoma (Wan et al, 2013), respectively.

\section{CONCLUSIONS}

The molecular mechanisms of EMAST have yet to be clearly unravelled. EMAST induction and its contribution to carcinogenesis may stem from both exposure to external mutagens and malfunctioning intrinsic cellular mechanisms. Experiments have suggested that long microsatellites with higher numbers of repeats may be prone to replication errors at higher frequencies compared with the shorter ones. However, the consequences of EMAST development in carcinogenesis require further investigation. The results from human solid cancers have led to proposed mechanisms involving DNA repair by TP53 and MSH3 and have suggested the immunological involvement of T cells, at least in CRC, although precise mechanistic understanding clearly requires further investigation.

The potential role of EMAST in early detection, prognostication and prediction has been poorly investigated. However, some findings have revealed the potential future use of this marker in cancer. Variations of specific lengths in certain polymorphic tetranucleotide repeats are associated with an increased cancer risk, as recently reported for breast cancer and hepatocellular carcinomas (Karimi et al, 2013; Wan et al, 2013). The high prevalence of EMAST in the early stages of some cancers, particularly those of the upper respiratory organs and lower urinary tract, may suggest EMAST as a potentially exploitable marker for preventive/early detection screening. In fact, in biopsies from endoscopically normal colons, MSI in mononucleotide and dinucleotide markers has been observed earlier than neoplastic changes (Tug et al, 2012). Although markers suggestive of EMAST have yet to be explored in the same manner, they EMAST markers may be found more abundantly, because EMAST occurs at higher frequencies. EMAST may also be generally related to environmental carcinogen exposure and may therefore serve as a marker of exposure or risk in certain cancers.

EMAST in the tissues of apparently tumour-free marginal sites of surgical resections has been correlated with disease recurrence (Temam et al, 2004). Therefore, EMAST in the tissues of histomorphologically normal (R0 resected) surgical cancer specimens could be used as a prognostic predictor of disease recurrence in head and neck cancers. Optimal marker selection may also lead to the feasibility of urine analysis for the early detection or postsurgical surveillance of patients with bladder cancer (van Tilborg et al, 2012).

Finally, the prognostic value of different forms of MSI in CRC warrants further research (Garcia et al, 2012). The 5-year recurrence-free survival trends for EMAST-positive and MSI-L tumours are worse compared with those of MSI-H tumours, suggesting differences in tumour biology that are currently not fully appreciated and that may have consequences for the use of the other available predictive and prognostic markers.

Taken together, these data suggest that EMAST should be further investigated for its potential use in screening and/or as a prognostic and predictive biomarker. In the fields of clinical and translational oncology, important steps need to be taken to improve the understanding of the role of EMAST in cancer. In our view, one unresolved issue remains regarding whether EMAST represents an 'innocent bystander' in cancer or an 'active partner' in carcinogenesis. Based on the emerging findings and cumulative reports discussed above, EMAST may have diverse roles in carcinogenesis and tumour biology at different tumour sites. Nevertheless, common underlying principles may be crucial for understanding cancer behaviour and may yield new tools for prevention, early detection or personalised treatment.

\section{ACKNOWLEDGEMENTS}

Work in our laboratory was supported by grants from the Folke Hermansens Cancer Fund, the Mjaaland Research Fund and the Institute for Surgical Sciences, University of Bergen, Norway. We apologise to those colleagues whose work could not be cited due to space limitations.

\section{CONFLICT OF INTEREST}

The authors declare no conflict of interest. 


\section{REFERENCES}

Ahrendt SA, Decker PA, Doffek K, Wang B, Xu L, Demeure MJ, Jen J, Sidransky D (2000) Microsatellite instability at selected tetranucleotide repeats is associated with p53 mutations in non-small cell lung cancer. Cancer Res 60(9): 2488-2491.

Arai H, Okudela K, Oshiro H, Komitsu N, Mitsui H, Nishii T, Tsuboi M, Nozawa A, Noishiki Y, Ohashi K, Inui K, Masuda M (2013) Elevated microsatellite alterations at selected tetra-nucleotide (EMAST) in non-small cell lung cancers-a potential determinant of susceptibility to multiple malignancies. Int J Clin Exp Pathol 6(3): 395-410.

Azzouzi AR, Catto JW, Rehman I, Larre S, Roupret M, Feeley KM, Cussenot O, Meuth M, Hamdy FC (2007) Clinically localised prostate cancer is microsatellite stable. BJU Int 99(5): 1031-1035.

Burger M, Burger SJ, Denzinger S, Wild PJ, Wieland WF, Blaszyk H, Obermann EC, Stoehr R, Hartmann A (2006a) Elevated microsatellite instability at selected tetranucleotide repeats does not correlate with clinicopathologic features of bladder cancer. Eur Urol 50(4): 770-775.

Burger M, Denzinger S, Hammerschmied CG, Tannapfel A, Obermann EC, Wieland WF, Hartmann A, Stoehr R (2006b) Elevated microsatellite alterations at selected tetranucleotides (EMAST) and mismatch repair gene expression in prostate cancer. J Mol Med (Berl) 84(10): 833-841.

Catto JW, Azzouzi AR, Amira N, Rehman I, Feeley KM, Cross SS, Fromont G, Sibony M, Hamdy FC, Cussenot O, Meuth M (2003) Distinct patterns of microsatellite instability are seen in tumours of the urinary tract. Oncogene 22(54): 8699-8706.

Choi YD, Choi J, Kim JH, Lee JS, Lee JH, Choi C, Choi HS, Lee MC, Park CS, Juhng SW, Nam JH (2008) Microsatellite instability at a tetranucleotide repeat in type I endometrial carcinoma. J Exp Clin Cancer Res 27: 88.

Danaee H, Nelson HH, Karagas MR, Schned AR, Ashok TD, Hirao T, Perry AE, Kelsey KT (2002) Microsatellite instability at tetranucleotide repeats in skin and bladder cancer. Oncogene 21(32): 4894-4899.

Devaraj B, Lee A, Cabrera BL, Miyai K, Luo L, Ramamoorthy S, Keku T, Sandler RS, McGuire KL, Carethers JM (2010) Relationship of EMAST and microsatellite instability among patients with rectal cancer. J Gastrointest Surg 14(10): 1521-1528.

Diaz-Padilla I, Romero N, Amir E, Matias-Guiu X, Vilar E, Muggia F, Garcia-Donas J (2013) Mismatch repair status and clinical outcome in endometrial cancer: a systematic review and meta-analysis. Crit Rev Oncol Hematol 88(1): 154-167.

Garcia M, Choi C, Kim HR, Daoud Y, Toiyama Y, Takahashi M, Goel A, Boland CR, Koi M (2012) Association between recurrent metastasis from stage II and III primary colorectal tumors and moderate microsatellite instability. Gastroenterology 143(1): 48-50 e41.

Haugen AC, Goel A, Yamada K, Marra G, Nguyen TP, Nagasaka T, Kanazawa S, Koike J, Kikuchi Y, Zhong X, Arita M, Shibuya K, Oshimura M, Hemmi H, Boland CR, Koi M (2008) Genetic instability caused by loss of MutS homologue 3 in human colorectal cancer. Cancer Res 68(20): 8465-8472.

Karimi P, Hematti S, Safari F, Tavassoli M (2013) Polymorphic AAAG repeat length in estrogen-related receptor gamma (ERRgamma) and risk of breast cancer in Iranian women. Cancer Invest 31(9): 600-603.

Kim HS, Lee BL, Woo DK, Bae SI, Kim WH (2001) Assessment of markers for the identification of microsatellite instability phenotype in gastric neoplasms. Cancer Lett 164(1): 61-68.

Kim TM, Laird PW, Park PJ (2013) The landscape of microsatellite instability in colorectal and endometrial cancer genomes. Cell 155(4): 858-868.

Kupka S, Haack B, Zdichavsky M, Mlinar T, Kienzle C, Bock T, Kandolf R, Kroeber SM, Konigsrainer A (2008) Large proportion of low frequency microsatellite-instability and loss of heterozygosity in pheochromocytoma and endocrine tumors detected with an extended marker panel. J Cancer Res Clin Oncol 134(4): 463-471.

Lee SY, Chung H, Devaraj B, Iwaizumi M, Han HS, Hwang DY, Seong MK, Jung BH, Carethers JM (2010) Microsatellite alterations at selected tetranucleotide repeats are associated with morphologies of colorectal neoplasias. Gastroenterology 139(5): 1519-1525.

Lee SY, Miyai K, Han HS, Hwang DY, Seong MK, Chung H, Jung BH, Devaraj B, McGuire KL, Carethers JM (2012) Microsatellite instability, EMAST, and morphology associations with $\mathrm{T}$ cell infiltration in colorectal neoplasia. Dig Dis Sci 57(1): 72-78.

Lindstrom E, Shimokawa T, Toftgard R, Zaphiropoulos PG (2006) PTCH mutations: distribution and analyses. Hum Mutat 27(3): 215-219.
Pal T, Permuth-Wey J, Kumar A, Sellers TA (2008) Systematic review and meta-analysis of ovarian cancers: estimation of microsatellite-high frequency and characterization of mismatch repair deficient tumor histology. Clin Cancer Res 14(21): 6847-6854.

Perinchery G, Nojima D, Goharderakhshan R, Tanaka Y, Alonzo J, Dahiya R (2000) Microsatellite instability of dinucleotide tandem repeat sequences is higher than trinucleotide, tetranucleotide and pentanucleotide repeat sequences in prostate cancer. Int J Oncol 16(6): 1203-1209.

Saeterdal I, Bjorheim J, Lislerud K, Gjertsen MK, Bukholm IK, Olsen OC, Nesland JM, Eriksen JA, Moller M, Lindblom A, Gaudernack G (2001) Frameshift-mutation-derived peptides as tumor-specific antigens in inherited and spontaneous colorectal cancer. Proc Natl Acad Sci USA 98(23): 13255-13260.

Singer G, Kallinowski T, Hartmann A, Dietmaier W, Wild PJ, Schraml P, Sauter G, Mihatsch MJ, Moch H (2004) Different types of microsatellite instability in ovarian carcinoma. Int J Cancer 112(4): 643-646.

Sinicrope FA, Sargent DJ (2012) Molecular pathways: microsatellite instability in colorectal cancer: prognostic, predictive, and therapeutic implications. Clin Cancer Res 18(6): 1506-1512.

Stoehr C, Burger M, Stoehr R, Bertz S, Ruemmele P, Hofstaedter F, Denzinger S, Wieland WF, Hartmann A, Walter B (2012) Mismatch repair proteins hMLH1 and hMSH2 are differently expressed in the three main subtypes of sporadic renal cell carcinoma. Pathobiology 79(3): 162-168.

Subramanian S, Mishra RK, Singh L (2003) Genome-wide analysis of microsatellite repeats in humans: their abundance and density in specific genomic regions. Genome Biol 4(2): R13.

Temam S, Casiraghi O, Lahaye JB, Bosq J, Zhou X, Julieron M, Mamelle G, Lee JJ, Mao L, Luboinski B, Benard J, Janot F (2004) Tetranucleotide microsatellite instability in surgical margins for prediction of local recurrence of head and neck squamous cell carcinoma. Clin Cancer Res 10(12 Pt 1): 4022-4028.

Terrell RB, Wille AH, Cheville JC, Nystuen AM, Cohen MB, Sheffield VC (1995) Microsatellite instability in adenocarcinoma of the prostate. Am J Pathol 147(3): 799-805.

Tug E, Balaban YH, Sahin EK (2012) Mapping of microsatellite instability in endoscopic normal colon. Genet Test Mol Biomarkers 16(5): 388-395.

Umar A, Boland CR, Terdiman JP, Syngal S, de la Chapelle A, Ruschoff J, Fishel R, Lindor NM, Burgart LJ, Hamelin R, Hamilton SR, Hiatt RA, Jass J, Lindblom A, Lynch HT, Peltomaki P, Ramsey SD, Rodriguez-Bigas MA, Vasen HF, Hawk ET, Barrett JC, Freedman AN, Srivastava S (2004) Revised Bethesda Guidelines for hereditary nonpolyposis colorectal cancer (Lynch syndrome) and microsatellite instability. J Natl Cancer Inst 96(4): 261-268.

van Tilborg AA, Kompier LC, Lurkin I, Poort R, El Bouazzaoui S, van der Keur K, Zuiverloon T, Dyrskjot L, Orntoft TF, Roobol MJ, Zwarthoff EC (2012) Selection of microsatellite markers for bladder cancer diagnosis without the need for corresponding blood. PLoS One 7(8): e43345.

Wan J, Huang M, Zhao H, Wang C, Zhao X, Jiang X, Bian S, He Y, Gao Y (2013) A novel tetranucleotide repeat polymorphism within KCNQ1OT1 confers risk for hepatocellular carcinoma. DNA Cell Biol 32(11): 628-634.

Woenckhaus M, Stoehr R, Dietmaier W, Wild PJ, Zieglmeier U, Foerster J, Merk J, Blaszyk H, Pfeifer M, Hofstaedter F, Hartmann A (2003) Microsatellite instability at chromosome $8 \mathrm{p}$ in non-small cell lung cancer is associated with lymph node metastasis and squamous differentiation. Int J Oncol 23(5): 1357-1363.

Xu L, Chow J, Bonacum J, Eisenberger C, Ahrendt SA, Spafford M, Wu L, Lee SM, Piantadosi S, Tockman MS, Sidransky D, Jen J (2001) Microsatellite instability at AAAG repeat sequences in respiratory tract cancers. Int J Cancer 91(2): 200-204.

Yamada K, Kanazawa S, Koike J, Sugiyama H, Xu C, Funahashi K, Boland CR, Koi M, Hemmi H (2010) Microsatellite instability at tetranucleotide repeats in sporadic colorectal cancer in Japan. Oncol Rep 23(2): $551-561$.

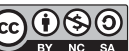

This work is licensed under the Creative Commons Attribution-NonCommercial-Share Alike 3.0 Unported License. To view a copy of this license, visit http://creativecommons. org/licenses/by-nc-sa/3.0/ 